\title{
Gearless Track-Friendly Metro with Guided Independently Rotating Wheels
}

\author{
Gianluca Megna $^{1} \cdot$ Andrea Bracciali $^{1}$ (I)
}

Received: 12 May 2021 / Revised: 26 September 2021/ Accepted: 9 October 2021/Published online: 18 November 2021

(C) The Author(s) 2021

\begin{abstract}
Track-vehicle severe interaction on track with small curve radius results in rail wear and corrugation, and wheel polygonization, which drain considerable resources for rail grinding and wheels re-profiling in metro lines. To reduce the damage caused by track-vehicle severe interaction, the paper analyzes the reasons leading to rail wear and then proposes an architecture of a metro vehicle with independently rotating wheels driven directly by permanent magnet synchronous motors. The architecture is axle guidance, offered by passive linkages, which ensures that all axles are oriented radially, while control strategy was kept as simple as possible, identifying only two basic traction conditions. The concept is first discussed and then validated through a comprehensive set of running dynamics simulation performed with a multibody software to evaluate rail wear and rolling contact fatigue in traction/ braking, coasting with different cant deficiency/excess conditions. The multibody dynamics simulation shows that the proposed architecture is virtually capable of avoiding both wear and rolling contact fatigue damages, and achieves the highest possible track friendliness. The concept of the proposed architecture is a track-fiendly metro architecture and could be a good reference for reducing rail-track interaction damages and maintainace cost.
\end{abstract}

Gianluca Megna and Andrea Bracciali contributed equally to the paper.

Andrea Bracciali

andrea.bracciali@unifi.it

1 Dipartimento di Ingegneria Industriale, Università di Firenze, via Santa Marta 3, 50139 Firenze, Italy

Communicated by Baoming Han.
Keywords Metro vehicle $\cdot$ Independently rotating wheels · Passive steering - Direct drive, permanent magnet synchronous motor, track friendliness

\section{Metro Vehicle Practice}

Conventional metros consist of one or more vehicles permanently connected (so-called traction units) that can be combined to assemble a train. Typically, traction units are made of either two or three cars resting on two bogies each, which may be completely autonomous (e.g. with a driver cab at both ends) or be designed to run exclusively coupled with other traction units.

Not all cars are equipped with motors. Modern power electronics allows the optimal use of adhesion, so service requirements in terms of traction and braking can be obtained with a partially driven vehicle. With the exception of very specific cases, performances are sufficient, although reduced, even in the case of failure of one traction chain in vehicles with $75 \%$ (3/4) or $66 \%$ (2/3) motor bogies. Regenerative braking is nowadays a standard; considering that a metro network has a large number of vehicles running on the line(s) at the same time, consistent energy savings are possible throughout the entire service timetable.

Looking at the bogie architecture and, generally speaking, at the running gear solutions, as already said, all the vehicles have long carbodies resting on two (motor or trailer) bogies. The drive chain includes three-phase alternating current $(\mathrm{AC})$ electric motors driven by $4 \mathrm{Q}$ pulse width modulation (PWM) inverters, gearboxes of several types (according to the relative motor-wheelset position) and a conventional wheelset typically equipped with brake discs. The most commonly used solution consists of driven 
vehicles with $\mathrm{B}_{0}{ }^{\prime}-\mathrm{B}_{0}{ }^{\prime}$ arrangement with one motor per axle. Axles are connected to the bogie frame with axleboxes and different types of primary suspension arrangement (either steel coil or rubber-steel springs), while the secondary suspension is inevitably of the airspring type to keep the vehicle floor at the correct height regardless of the payload (which can be very relevant for a metro).

\section{Influence of Bogie Architecture on Track Friendliness}

Although type testing may be accurate and extensive, tenders normally pay little attention to track-vehicle interaction. As a result, nearly all the metro lines in the world suffer from extensive high rail wear and low rail corrugation phenomena, and in some cases also from wheel polygonization phenomena.

Rail corrugation and wheel polygonization generate noise and vibrations that are perceived as a major problem by the operating company (typically owned by the municipality of the city where the metro is located), by the passengers and by the citizens living close to the line. Corrugation, in fact, cannot be definitively cured, and the only temporary remedy is rail grinding. Unless specific provisions are taken, such as the use of friction modifiers to reduce work dissipated at the wheel-rail contact and the growth speed of the corrugation, the problem reappears quickly (often with times in the order of weeks [1]) and drains considerable resources to be kept under control. Clearly, frequent rail grinding and wheels re-profiling has an adverse effect on the life of the components, generating high direct and indirect costs.

The most classical effects of rail corrugation are:

- High noise, both in the stations and on board the train;

- High ground-borne vibrations, transmitted to the buildings surrounding the (underground) line;

- Failure of vehicle components (especially unsprung parts).

It is widely accepted that corrugation is based on a wavelength-fixing mechanism that depends on a large number of parameters not yet fully understood. Nevertheless, the evidence says that corrugation in tangent track is limited to those cases where evident abnormalities in the homogeneity of track support exist, such as muddy sleepers typically appearing in old tunnels where water drainage may present a problem.

Although finding a corrugated tangent track is challenging, not much effort has to be spent finding a corrugated curve. Curvature has a dominant importance: low rails in nearly all curves with a radius lower than 300/400 $\mathrm{m}$ are corrugated. Though these curvatures may be rare in main lines, they are, on the contrary, very frequent in metro lines.

Corrugation in metros is particularly relevant as friction coefficient at the wheel-rail contact may be particularly high (up to $f=0.8$ [2]), and the conventional bogie architecture inevitably leads to high creepage at the wheelrail contact patch. Angle of attack (AOA) of the leading wheelset of a bogie is particularly high; as a result, gauge spreading forces [3] generate potentially high wear on the outer wheel (that can be mitigated with proper flange lubrication) and stick-slip phenomena on the inner wheel. The trailing wheelset runs typically more centred, although high longitudinal forces may be responsible for corrugation growth [4].

\section{Design of an Innovative Metro Vehicle}

\subsection{Scope of the Work}

The aim of the work is to design and validate the concept of a new metro vehicle focussing on track friendliness, robustness and architecture simplicity. This work should be seen as a preliminary step towards the definition of a vehicle concept rather than a complete design.

As will be seen, the concept is based on technologies that are either existing in the metro industry or derived from other vehicles with the proper modifications. Although integrating known technologies, the architecture is new and a demonstrator would certainly be useful to fully appreciate advantages regarding actual service.

\subsection{The Reference Conventional Metro Train}

To select a valid comparison vehicle, the metro described by one of the authors in papers [5] and [6] was used as an example of a conventional train (hereafter called CONV) [6]. The architecture of the train is shown in Fig. 1, where driving trailers and motor cars can be seen. The train is in service in the network of a major European city and can be considered as a benchmark train. In fact, new trains from the same worldwide manufacturer continue to use exactly the same architecture.

The mechanical properties of the CONV train will be discussed below.

\subsection{Gearless Track-Friendly Metro Train with Guided Independently Rotating Wheels}

The basic elements of the concept of gearless TrackFriendly Metro (TFM) train with guided independently rotating wheels are described in detail below. 


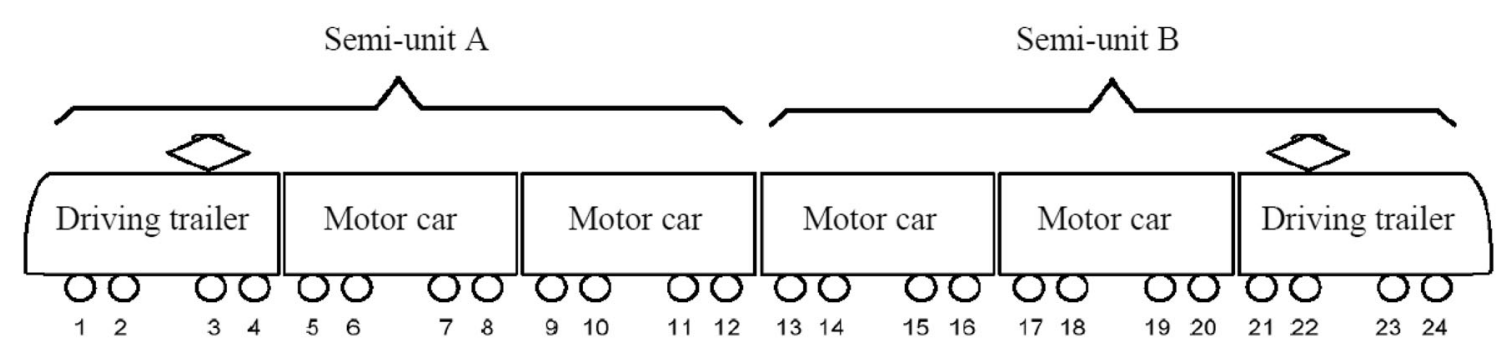

Fig. 1 Architecture of the conventional (CONV) metro train considered as a benchmark vehicle (from [5])

- The use of portal axles (axlebridges) with independently rotating wheels (IRW), passively steered by the carbodies;

- An articulated layout with short carbodies to keep axle load within the limits of current metro practice;

- A direct drive motor (DDM) solution which eliminates the need for gearboxes.

\subsubsection{Single Axle and Passive Steering}

Ordinary bogies rotate around a "physical" (bearing) or "virtual" (elastic elements) vertical pivot with low restraining torque. Advantages of bogie vehicles compared with two-axle vehicles are so evident that nearly all the vehicles today are equipped with bogie. Where curvature is high, such as in many metro lines, many designers tried to decrease AOA to reduce the aforementioned related problems by "steering" the bogie and/or the axles.

The most straightforward way to reduce the AOA is to increase the freedom of the wheelsets by reducing the stiffness of the longitudinal primary suspension $k_{x}$, thereby lowering yaw stiffness and improving self-steering capability. This measure has an obvious drawback in the similarly reduced stability at high speed given that, as is known, guidance and stability dictate opposite requisites [3] for $k_{x}$. Moreover, more recently it was found that traction forces applied to driven wheelsets can impair the efficacy of a smaller $k_{x}$. References [7] and [8] show, in fact, that traction forces tend to make the wheelsets run parallel regardless of how soft the primary suspension is longitudinally. A measure that could be valid for a trailer car is therefore useless for a motor car.

The only alternative is to make recourse to forced steering. All forced steering solutions can be classified as either "active" or "passive". Active steering requires a control strategy and a closed loop system, in which the current position of the axle/bogie is sensed by proper transducers that feed a control system that in turn commands some actuators to reach the desired angular position. To the author's knowledge, active steering is not currently available in commercial vehicles, even though the scientific literature on the subject is huge.
Passive steering of bogies does not solve the problem for metro vehicles for two reasons: first, because the carbodybogie frame torque (yaw or z-axis) is very limited due to of the use of airsprings; and second, because any steering mechanism not acting on single wheelset does not solve the problem generated by the parallelism of the wheelsets.

In this research, a single wheelset passive steering solution was used. Reasons for this choice lie mainly in reliability and availability of the steering system. A system made of rods and pins suffers much fewer failures than an active system, and safety analysis involves only mechanical components, resulting in easier acceptance by authorities than a rather complex system made of sensors, logic, actuators and so on.

A classical solution for steering is one in which the carbody steers the bogie frame, which in turn steers the wheelsets [9]. The solution chosen here is inspired by the well-known (and maybe simpler) principle of the Talgo portal axle (Fig. 2), called rodal by the company, in which a single axle equipped with IRW is steered by a Watt's linkage connected to the adjacent carbodies $([10,11])$. The main advantages that Talgo reached with the rodal were:

- Lowest longitudinal and lateral forces at the wheel-rail contact guaranteed by the freely rotating wheels and the radial alignment of the rodal;

- Low-floor solution allowed by the absence of the conventional axle;

- Passive tilting of the carbodies as the secondary suspension is located on the top of long columns connected to the lower part of the rodal.

To be properly steered, a rodal needs two carbodies acting on the linkages, and therefore the first and the last axle of a trainset cannot be steered by a missing carbody. The solution adopted in the research is the classical crossbracing [3] interconnecting the wheelsets of a two-axle vehicle. Although cross-bracing has strong limitations in tram vehicles which run on lines without transitions between straight track and constant radius curves, it works well where curve radii are relatively large compared with the wheelbase of the vehicle and where transitions are present. This last is always the case for metro lines, where 

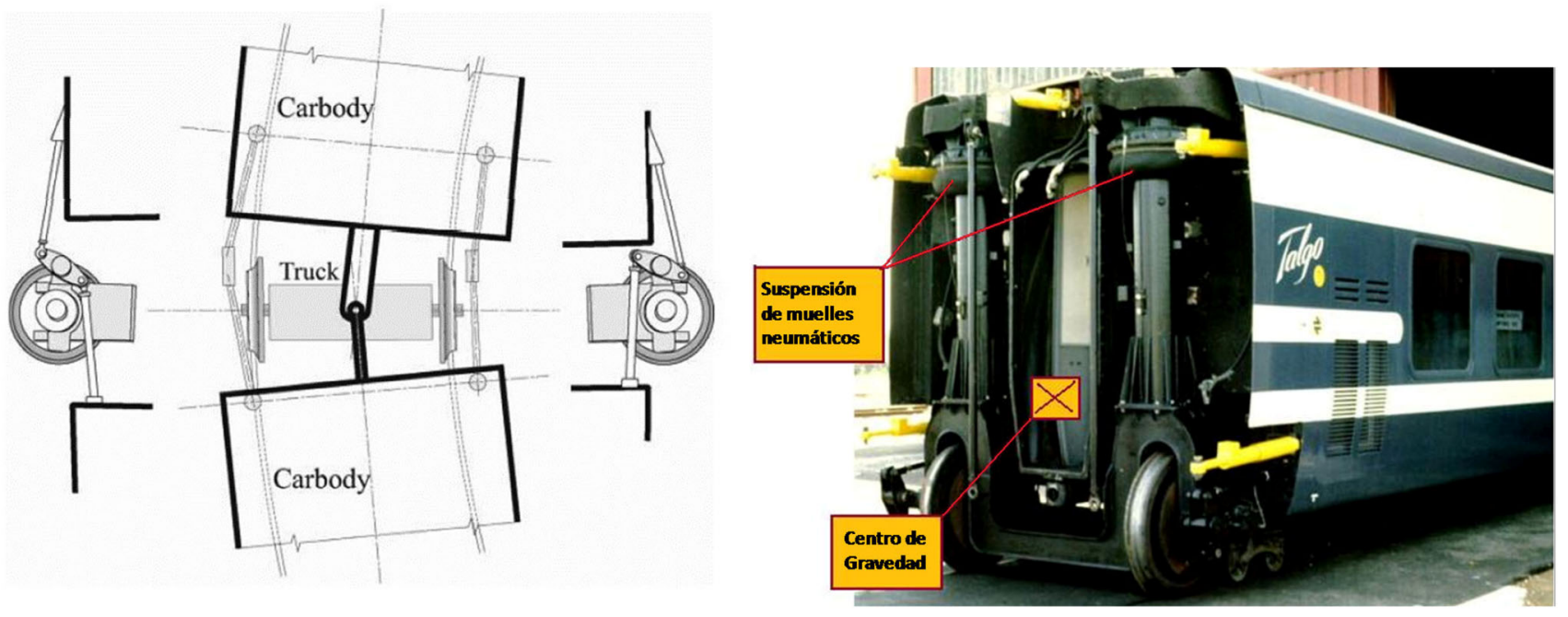

Fig. 2 Left: mechanism to steer IRW developed by the Spanish company Talgo. Right: a rodal where columns and high secondary suspensions can be clearly seen (from [10])

abrupt curvature changes must be avoided without exceptions.

Due to the particular shape of the rodal, no driven wheels were ever developed by Talgo, whose trains are always hauled by "conventional" locomotives with bogies, a solution that has no meaning for metros. To the authors' knowledge, the Talgo architecture was used only on mainline vehicles with the notable exceptions (Fig. 3) of the Breda Costruzioni Ferroviarie VLC tram in Lille
(France) with trailed wheels in the early 90s [12] and of the Siemens ULF tram in Wien (Austria) and in Oradea (Romania) with driven wheels [13][13], in both cases to achieve a fully low-floor architecture. No applications in metro vehicles were found.

As said before, low-floor solutions are of no interest in metro vehicles, and cant deficiency can be properly addressed at a design stage (especially for fully automated metros), making roll angle much less important than in
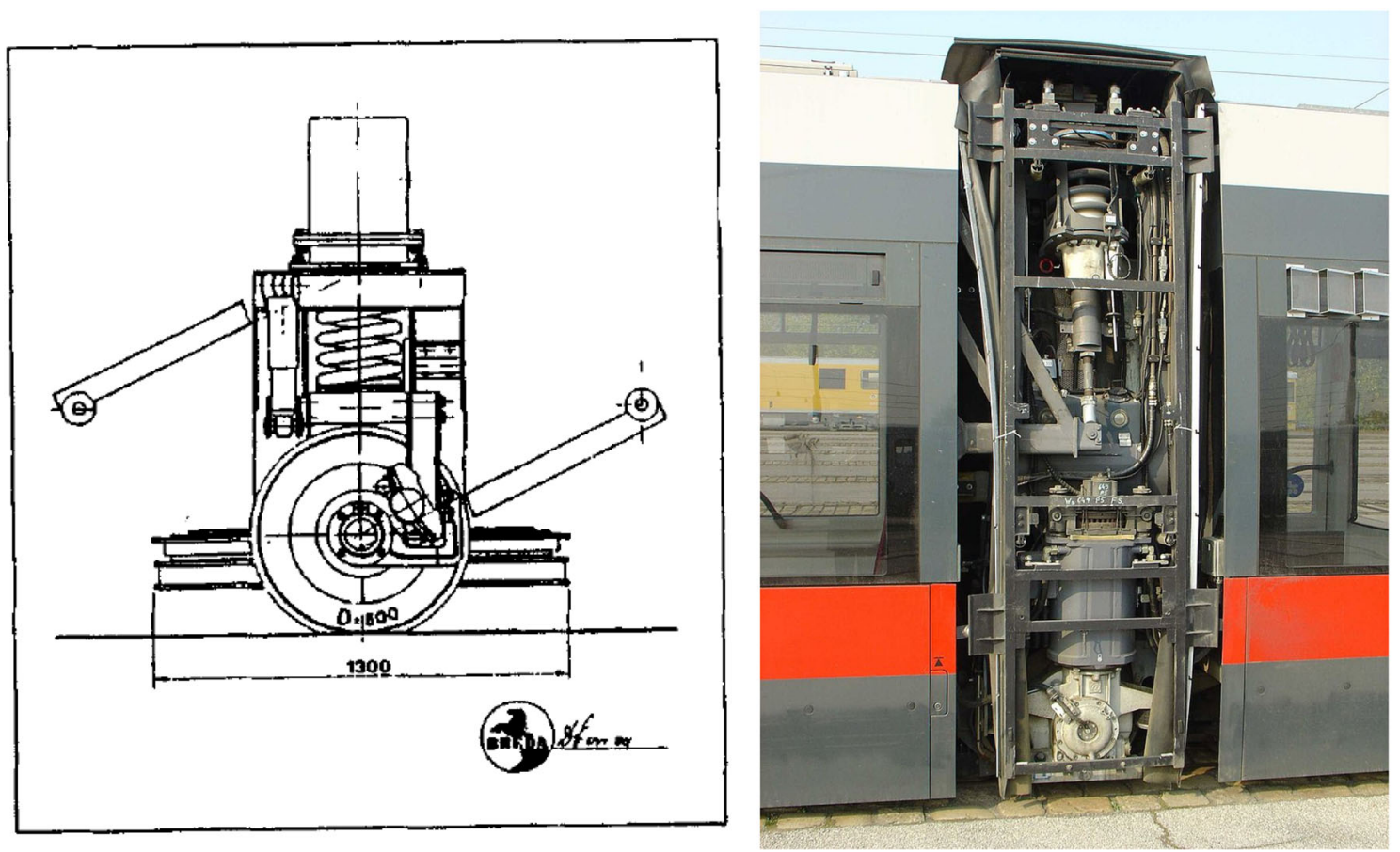

Fig. 3 Left: trailed "Talgo-like" IRW arrangement on VLC tram/* MERGEFORMAT [12]. Right: driven wheel in the ULF tram ${ }^{*}$ MERGEFORMAT [13] 
mainline vehicles that run on an infrastructure shared by many types of vehicles. The solution adopted therefore takes the steering concept as the only very high-value property of the rodal solution for metros, aiming to dramatically reduce wheel-rail forces. As will be seen, where cant deficiency is zero, only spin creepage (negligible) exists at the wheel-rail contact and there is virtually neither frictional work nor wear/rolling contact fatigue (RCF) problems.

\subsubsection{Vehicle Layout}

The adoption of single axle heavily impacts vehicle layout because of the limitations on axle load. With the aim of keeping the axle load less than or equal to $12 \mathrm{t}$, only shorter carbodies can be used.

A comparison of layout characteristics of the $C O N V$ and the TFM trains took into account many parameters, such as the overall length, number of carried passengers, door size and number, traction/braking performances and so on.

Considering all these main factors, the design was considered to be satisfactory when TFM reached the configuration compared to CONV presented in Table 1. This led to 19 cars with 20 axles (car length $5.65 \mathrm{~m}$ ), as shown in Fig. 4, with the same overall length $(108 \mathrm{~m})$ and the same axle load $(12 \mathrm{t})$. It can be seen that the number of passengers slightly decreased, although the very different conditions in the gangways (vehicles are connected through spherical joints with much lower displacements and rotations in that area) could lead to an increase in seats or to different boarding conditions.

The resulting much shorter vehicles have both positive and negative impacts on costs and on operation that will not be addressed in detail as this analysis is beyond the scope of this paper. Shorter cars result in smaller

Table 1 Comparison of the main characteristics of CONV and TFM metro trains

\begin{tabular}{lll}
\hline Vehicle name & CONV & TFM \\
\hline Architecture & Bogies & Rodals \\
Number of cars & 6 & 19 \\
Car length & $18 \mathrm{~m}$ & $5.65 \mathrm{~m}$ \\
Number of bogies & 12 & N/A \\
Number of axles & 24 & 20 \\
Overall length & $108 \mathrm{~m}$ & $108 \mathrm{~m}$ \\
Total number of passengers & 1208 & 1143 \\
Axle load/wheel load & $12 \mathrm{t} / 6 \mathrm{t}$ & $12 \mathrm{t} / 6 \mathrm{t}$ \\
Number of driven axles & 24 & 20 \\
Fully loaded mass & $288 \mathrm{t}$ & $240 \mathrm{t}$ \\
\hline
\end{tabular}

overthrows, lower gauging problems and, as a consequence, the possibility of widening the carbodies with the same gauge in curves if track-platform relative geometry can be fixed (e.g. by shifting the track to accommodate wider carbodies). From a tare load point of view, it can be said that short carbodies are strong and stiff enough to allow a drastic reduction in their structural mass. Rodals, $12 \mathrm{t}$ per axle, are particularly light, and the empty vehicle mass benefits largely from the new architecture. From a manufacturing, handling and logistics point of view, short carbodies allow an easier design of the vehicle mounting and testing.

\subsubsection{Gearless Drive with Permanent Magnet Synchronous Motors (PMSM)}

The use of direct (gearless) transmission is not new in tram vehicles. An interesting application can be found in the ABB Variotram (today Stadler Variobahn) introduced in 1993 in which the wheel tyre was directly connected to the rotor of the electric motor [15] (Fig. 5). In this application, the motor is totally unsprung.

A single wheel transmission, although not direct, worth mentioning is that of the aforementioned Siemens ULF. Krettek [14] reports on the difficulties in trying to let the wheels running centred, as the rodals tended to steer keeping a wheel flange in continuous contact with the rail. The trick used by control engineers at that time was to superimpose a sine "disturbance" to motor currents in order to produce an artificial Kalker's motion.

The reason for such a problem can be attributed to the intrinsic working condition of three-phase AC asynchronous motors, which need some slip between the rotating magnetic field and the rotor to induce currents in the rotor itself to output a net torque. As no two motors, two gearboxes or two wheels are exactly the same, the speed of the two wheels on a rodal differs slightly. As shown below, the wheel-rail creepage that allows the adhesion limit to be reached is around 1.5-2\%, smaller than the slip of the motor. As a consequence, the too "soft" mechanical characteristic curve of the asynchronous motor is intrinsically unable to finely control creepage and, therefore, speed.

Due to recent market evolution, many PMSM AC brushless hub motors are available today for the automotive market. These motors have a fixed hub (stator) with windings and a rotating part (rotor) equipped with permanent magnets. They were developed to drive electric and hybrid cars and are therefore "hidden" in the wheel web with a maximum external diameter of $17^{\prime \prime}-19^{\prime \prime}$ (Fig. 7). Direct coupling leads to a gearless vehicle, eliminating gearboxes. An important property of PMSMs is the intrinsic braking feature also in case of absence of electric 
Fig. 4 Sketch of the layout of the $C O N V$ vehicle (6 cars, top) and of the TFM vehicle (19 cars, bottom)
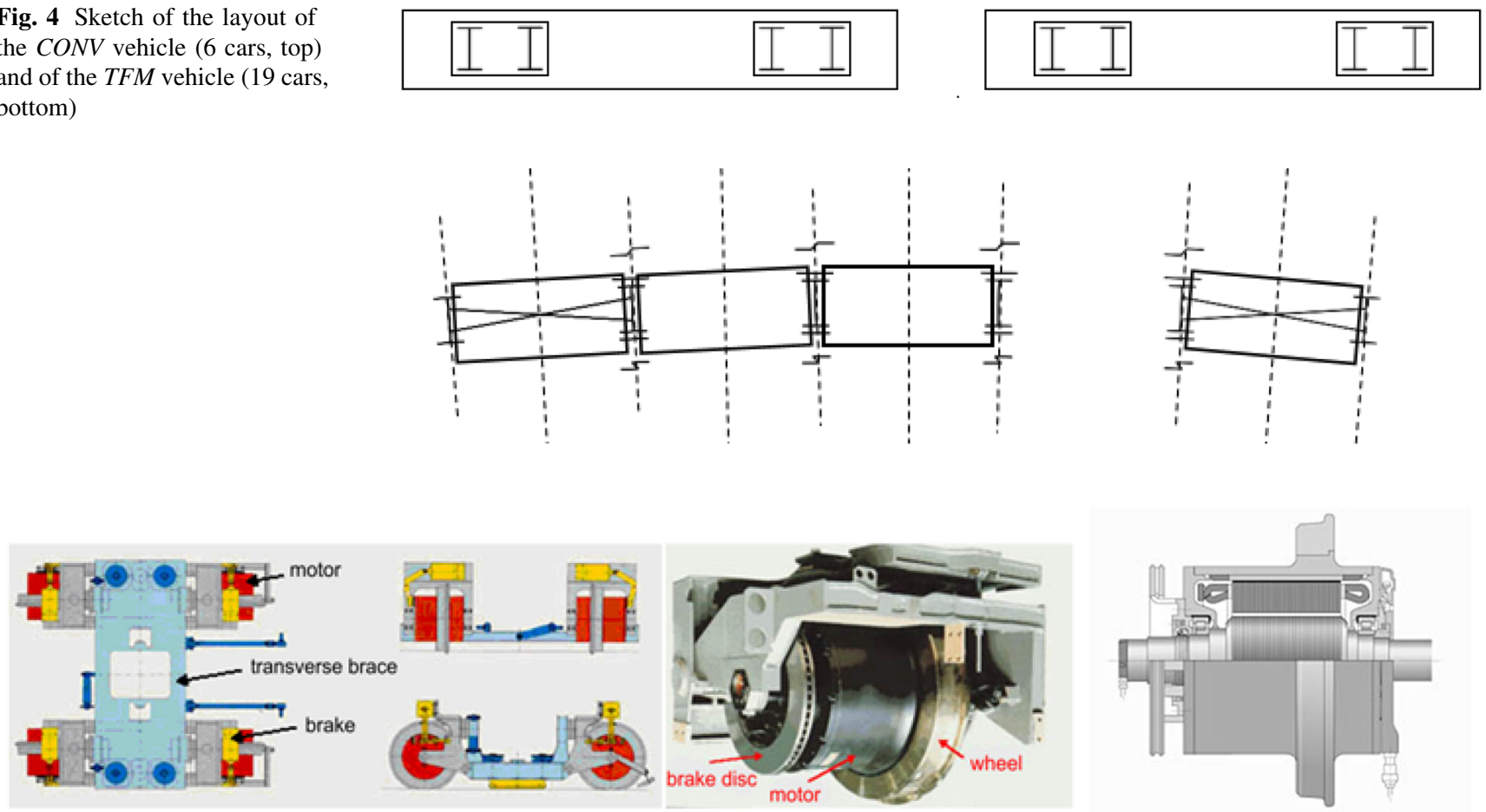

Fig. 5 The Variotram hub motor wheel [15]

power, resulting in a fail-safe operation. 4Q inverters allow regenerative braking in the whole range of speeds.

The application of direct drive with PMSMs has been approached more recently by Škoda, which equipped its ForCity $15 \mathrm{~T}$ tram with PMSMs connected to the wheel hub with a flexible shaft that compensates for different vertical movements of the tyre and of the bogie frame to which the motor is connected ([16] and [17], see Fig. 6). In fact, the elastic wheels provide a suspension stage that, although limited, is certainly beneficial for the motor health. Details on how the motor control was implemented can be found in Ref. [18].

While the size of outboard-mounted motors on trams is limited by the small diameter of the wheels and the little space available up to the allowed gauge (and in any case, there is no other way to install motors in a low-floor vehicle), for the metro considered in this work, fewer problems exist as:

- The motor does not have to fit in the wheel web when web-mounted brake discs are present;

- The diameter can be increased considerably compared with tram vehicles;

- The axial width is not limited by low-floor requirements.

Automotive requirements are much lower than metro vehicle requirements, but a market survey conducted with several possible suppliers (see e.g. Fig. 7) led to the conclusion that motors with the correct size can easily provide a maximum starting torque of around $4500 \mathrm{Nm}$ per wheel. A sketch of the volume occupied by a PMSM supplying a total starting torque of $9000 \mathrm{Nm}$ per axle is shown in Fig. 8.
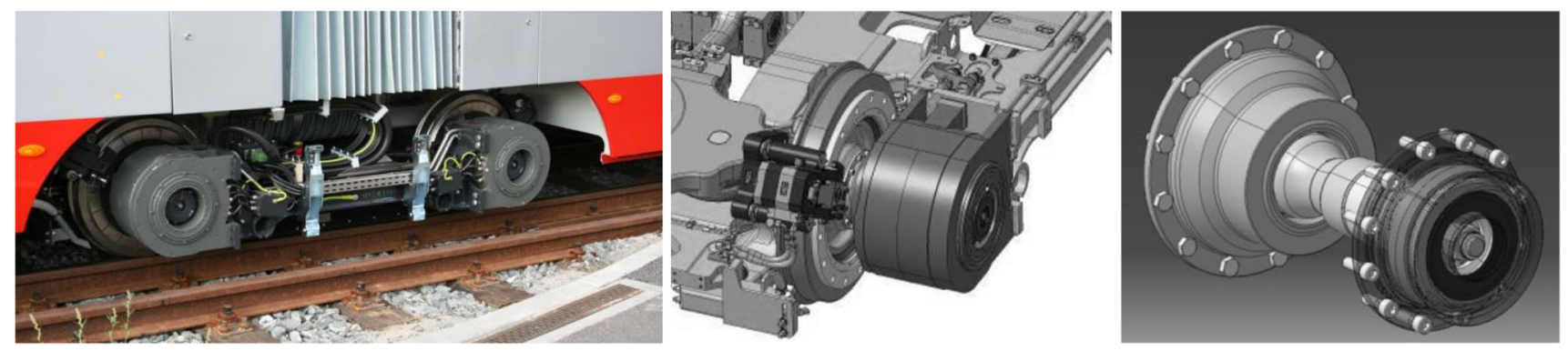

Fig. 6 Gearless transmission of Škoda ForCity 15 T [17] 

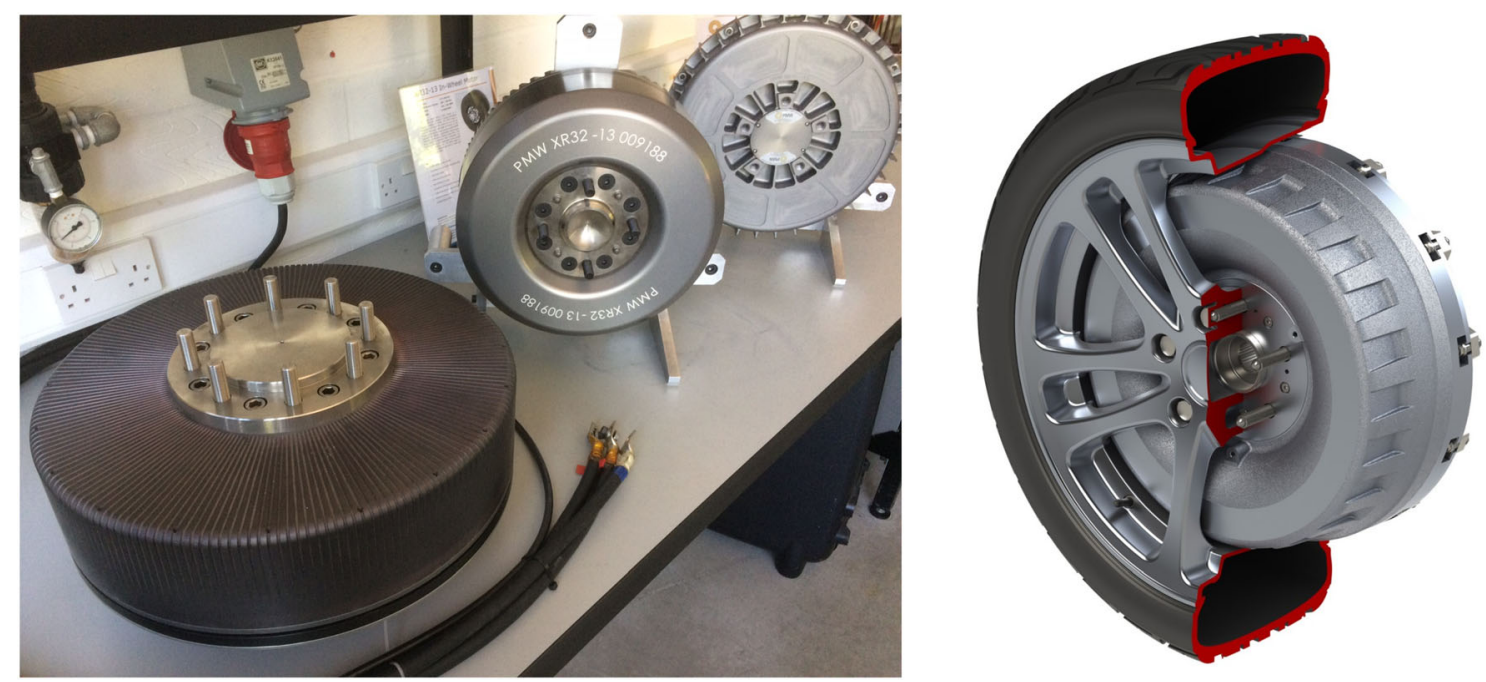

Fig. 7 PMSM motors (left) and a hub motor wheel (right) for automotive applications (from https://www.printedmotorworks.com).
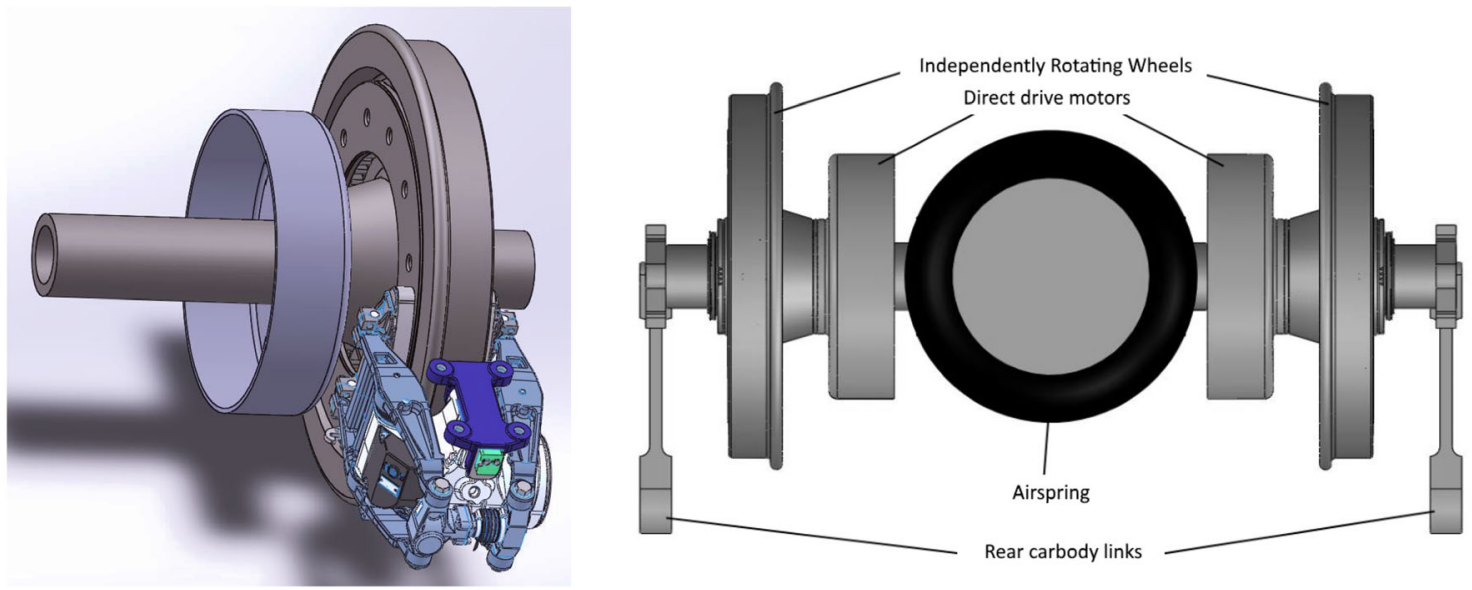

Fig. 8 Sketch of a wheel with a direct drive motor and a brake disc installed on the web. Braking system and rodal linkages are only partly represented

While there is plenty of scientific literature on motors control to get a desired steering performance, a relatively simple motor driving strategy was forecasted. Knowledge of the vehicle position along the line with a very good approximation, intrinsic in any automatic train operation (ATO) system, makes it possible to switch between two well-defined and easy-to-obtain driving strategies:

- In tangent track, wheels are driven in position mode, i.e. the rotation angles of right and left wheels are controlled to be exactly the same. This mode mimics the numerical control of $X-Y$ axes of the table of milling machine tools running through a $45^{\circ}$ diagonal line regardless of cutting forces. As the wheels rotate exactly at the same speed, the behaviour of the rodal is identical to a conventional wheelset, with the wellknown centring effect given by local and equivalent conicities that ensures the absence of continuous flange contact.

- When the curve radius is lower than a given limit (see Annex Q "Radial steering index" of [19] for further information on how this value can be found), radial steering of the "equivalent rigid wheelset" offered by the profiles would be insufficient in any case. The wheels are then "released", and the control enters the torque mode that imposes the same torque on both wheels regardless of their speed. No attempts are made to try to "steer" the rodal by imposing different torques to the wheels, as this is deemed to be uselessly complex and without practical advantages. The results may be non-optimal, but this strategy is easily obtainable and works sufficiently well as verified below. 


\section{Assessment of Track Friendliness}

\subsection{Scope and Methods}

The first step in the validation of the concept of the TFM vehicle was to compare its track friendliness with that of the $C O N V$ metro vehicle. This comparison has nearly no sense in classical-type test configurations (straight track, both uphill/downhill and flat) as wheel-rail traction and braking forces depend on inertia forces that are functions only of the mass and the acceleration/deceleration of the trainset. In these conditions, all architectures are nearly equivalent and there is no reason to perform any comparison. No straight track simulations were then planned.

Simulations were instead conducted to investigate "severe" situations where the advantage of the proposed solution may be decisive, impacting on high rail gauge face wear and on low rail corrugation.

Sharp curves $(R=200 \mathrm{~m})$ with/without high cant $(160 \mathrm{~mm})$ with/without a high uphill slope $(50 \%$ ) were investigated first. Although these conditions may appear extreme, they generate such large problems wherever they are encountered that they are in any case useful to be investigated. Less demanding situations were investigated as well, varying the curve radius in a horizontal track to observe the behaviour with and without cant deficiency. Both starting and coasting scenarios were simulated to confirm the expected advantages arising from the TFM architecture.

Differences between $C O N V$ and $T F M$ were then investigated in the following areas:

- Useful tractive effort can make the difference in sharp, canted, steep uphill curves. CONV was expected to exhibit high AOAs that "waste" available adhesion with lateral and longitudinal wheel-rail contact forces that arise from the rigid structure of the bogie. In the $T F M$ vehicle, full traction is available when the traction control is applied in torque mode;

- The absence of unnecessary creep forces and the radial attitude of the rodal may dramatically reduce rail damage generated by TFM, even in coasting conditions. As no traction is applied, simulations immediately provide an estimation of the energy lost at the wheelrail contact by observing the speed in a continuous and steady curving condition;

- The advantage of the TFM over the CONV vehicle was validated in a wide range of curve radii. In fact, it is known that, while wear and corrugation appear mostly on high and low rail of sharp curves, respectively, RCF defects mostly grow on mild curves where wear is limited.
Different indicators are available to determine the advantages of TFM over CONV. Those chosen in this work are:

- The AOA, which gives an indication of the steering attitude of the wheelset and the proneness to high wear on the rail gauge face and of the wheel flange;

- Wheel creepage $\left(\gamma_{x}, \gamma_{y}\right)$, creep forces $\left(T_{x}, T_{y}\right)$ and the resulting wear number $W=T \gamma=T_{x} \gamma_{x}+T_{y} \gamma_{y}$ which are related to the wheel-rail damage [20];

- The derailment ratio $Y / Q$ evaluated at the outer wheel of the leading axle to investigate potentially dangerous situations as IRW is intrinsically less safe than conventional wheels in this respect.

Wear numbers by themselves are not sufficient to describe rail damage as a model is needed to relate these two quantities. It was decided to use the models developed by Burstow [21] and Öberg [22] to estimate the damage in sharp and mild curves. This model identifies the range of $W$ for which RCF damage is dominant over wear (Fig. 13).

Wheel and rail profiles have a deep impact in forces exchanged at the contact point(s). To avoid double contact problems, S1002 profile was selected for wheels and 60E1 rails laid 1:40 with a standard track gauge of 1435 were used. The absence of gauge widening (nowadays only used in depots for minimum curve radius of around 70-80 m) also in the sharp curve simulated $(R=200 \mathrm{~m})$ keeps the bogie of the vehicle $C O N V$ more centred, reducing lateral forces also at equilibrium or in cant excess conditions. Although not strictly applicable for metros, the maximum cant value $(160 \mathrm{~mm})$ was selected according to European regulation for mixed traffic on ballasted main line tracks as described in Ref. [23].

Wear numbers were evaluated for $C O N V$ vehicle on a per bogie basis as the carbody-bogie frame rotational resistance was set to zero (a condition that helps steering) and the two bogies of the same car exhibit the same behaviour. As all the cars in the trainset are identical, the results per bogie were multiplied by the number of bogies (12) of the full trainset to get the overall wear number.

The simulation of $T F M$ vehicle was initially limited to a 5-car symmetrical trainset to reduce simulation times and then extended to 19-car full composition. Some details of the models are shown in Figs. 9 and in 10.

\subsection{Adhesion Consideration and Anti-spin Simulation}

All simulations were planned with an $f=0.4$ adhesion coefficient mainly to be consistent with conventional running dynamics simulations. Nevertheless, attention should be paid to the evidence that in dry, hot, long metro tunnels adhesion coefficient can be even higher than $f=0.6$. Rail 

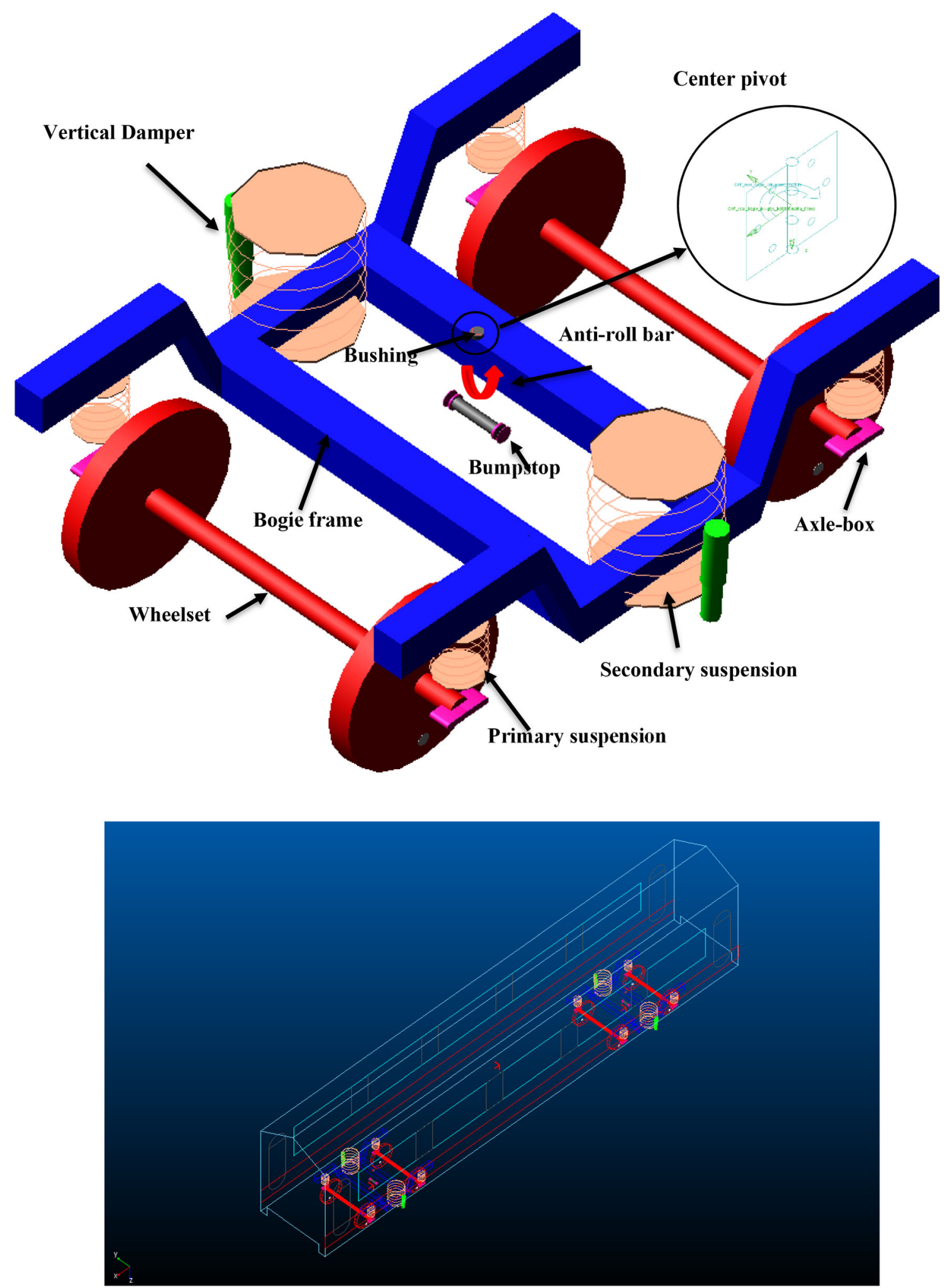

Fig. 9 Multibody model of the bogie (top) and of a full car (bottom)of the CONV train

damage can therefore be underestimated, such that any difference between the two vehicles can be amplified by more "sticky" conditions as the TFM vehicle has more favourable rolling conditions than do CONV vehicles, in which sliding friction is more evident in sharp curves. 
Fig. 10 Multibody model of the rodal (top) and of the reduced five-car formation (bottom) of the TFM train
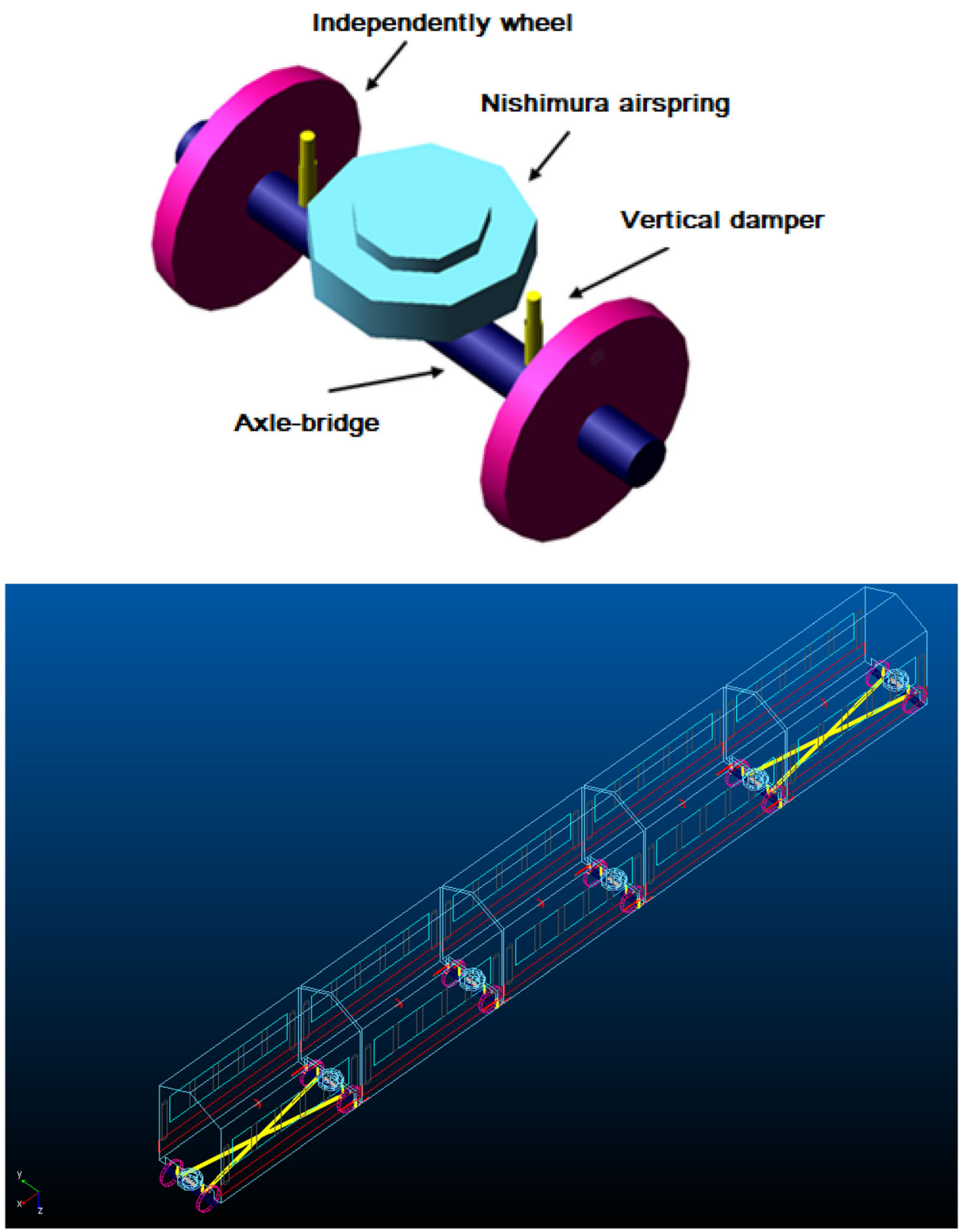

The software package used for the simulations (VI-Rail [24]) allows modelling of the tangential wheel-rail contact defining different values of friction coefficients, which could be constant or variable in function of the creepage. In the second case, it is therefore possible to define a saturation limit for the traction curve according to the maximum longitudinal creep until the adhesion force is reached. FASTSIM is used as the creep forces calculation method [25].

Modern single axle traction controls apply torque gradually at start. Torque values increase up to the desired value, while anti-spin devices are designed with some tolerance to accommodate for limited wheel diameter. As a real-life example, a locomotive with nominal wheels diameter $D_{n}=1100 \mathrm{~mm}$ may tolerate a maximum diameter difference of $25 \mathrm{~mm}$, which results in an rpm difference of $\pm 0.0116= \pm 1.16 \%$. Larger $\mathrm{rpm}$ differences are perceived by the control as spin or skid, interrupting traction or braking.

Simulations were conducted with a saturation curve that has a maximum of $f=0.4$ for a longitudinal creep $\gamma_{x}=$ $1.65 \%$, while it drops down to $f=0.01$ when the creep becomes $\gamma_{x}=1.70 \%$. This approximation tends to mimic the behaviour of anti-spin systems normally installed on motor vehicles.

Starting from still, torque was increased until slipping conditions were reached, and as no anti-spin control was applied, the train gradually slowed down to a stop while 
wheels continued to spin (this is acceptable only numerically). This was a method to find the maximum applicable torque in "non-ordinary" unfavourable conditions.

\subsection{Validation Plan and Results}

The validation plan consisted of three different scenarios:

- Start on steep, sharp curve $(R=200 \mathrm{~m}, i=50 \%$, $v=0)$ with highly canted track $\left(h=h_{d}=160 \mathrm{~mm}\right.$, case "SC");

- Start on steep, sharp curve $(R=200 \mathrm{~m}, i=50 \%$, $v=0)$ with flat track ( $h=h_{d}=0 \mathrm{~mm}$, case "SF");

- Coasting in horizontal curves of different radii with high cant deficiency $\left(h_{d}=+153 \mathrm{~mm} / a_{n c}=+1 \mathrm{~m} / \mathrm{s}^{2}\right.$, case " $\mathrm{R}_{+1}$ ") and at balancing speed ( $h_{d}=a_{n c}=0$, case " $\mathrm{R}_{0}$ ").

For SC case, the simulation was conducted starting with a small torque on a flat, straight track; then the vehicle started curving and climbing on a transition until it stopped in the steep, circular curve as the torque was insufficient to climb. When the speed zeroed, a predetermined torque was applied per axle. For vehicle CONV, this results in longitudinal (traction) forces depending on local contact conditions (different for right and left wheels), while for vehicle TFM (on which torque control is applied) the longitudinal forces are exactly the same as the wheels are independently driven.

The torque was increased until wheel slip was detected on vehicle CONV. This resulted in a maximum torque of $4500 \mathrm{Nm}$ per axle (equivalent to $4500 \times 24$ / $288=375 \mathrm{Nm} / \mathrm{t}$ ) and in an acceleration of $0.33 \mathrm{~m} / \mathrm{s}^{2}$. The same torque was applied on each rodal of TFM $(2250 \mathrm{Nm}$ per wheel), resulting in the same specific torque $(4500 \times 20 /$ $240=375 \mathrm{Nm} / \mathrm{t}$ ). The fact that $T F M$ has a lower resistance to motion led to a slightly higher acceleration of $0.35 \mathrm{~m} / \mathrm{s}^{2}$.

The same torque (4500 Nm per axle) was applied in the SF scenario, identical to the previous one but for the cant (i.e. in initial balanced conditions).

A summary of the results for both the front bogie of vehicle CONV (front and rear) and for the short five-car TFM trainset (axles 1-6) is presented in Table 2. Longitudinal $T_{x} \gamma_{x}$, lateral $T_{y} \gamma_{y}$, total $W$ and the corresponding rail damages are reported. Moreover, to guarantee a fair comparison, the results of the front bogie of $C O N V$ are presented for six axles. As expected, independently from the initial condition, canted or flat track, the CONV vehicle shows high values of $T_{y} \gamma_{y}$ on the front axle and high values of $T_{x} \gamma_{x}$ on the rear axle, resulting in severe wear (negative damage values) for both high and low rail. On the contrary, wheels of vehicle B are often below the threshold of $15 \mathrm{~J} / \mathrm{m}$ for which no damage is introduced in the rail. This is especially true for those situations where vehicle runs at the equilibrium speed.

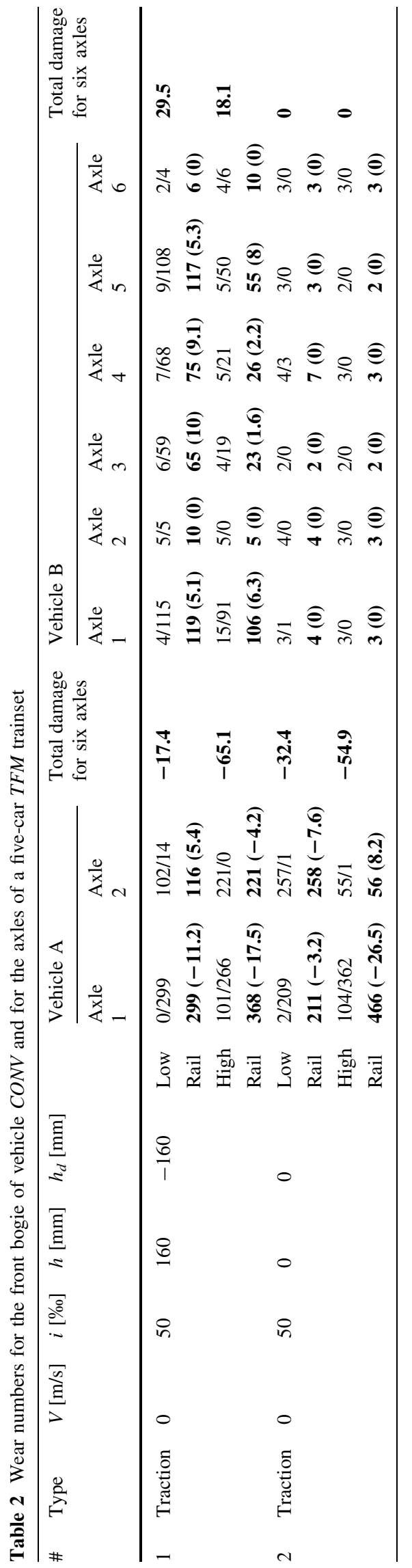


Table 3 Forces $T_{x}$ and $T_{y}$ in the local contact reference system and lateral force $Y$ in the global reference system for the front bogie of the vehicle $C O N V$

\begin{tabular}{llllllll}
\hline & Case & $T_{x}[\mathrm{~N}]$ & $T_{y}[\mathrm{~N}]$ & $Y[\mathrm{~N}]$ & $\begin{array}{l}T_{x} \gamma_{x} \\
{[\mathrm{~J} / \mathrm{m}]}\end{array}$ & $\begin{array}{l}T_{y} \gamma_{y} \\
{[\mathrm{~J} / \mathrm{m}]}\end{array}$ & $\beta\left[^{\circ}\right]$ \\
\hline Wheel 1L & $\mathrm{SC}$ & -9660 & 15,860 & $-23,820$ & 101 & 266 & 46.2 \\
(high rail) & $\mathrm{SF}$ & $-11,810$ & 22,630 & $-30,700$ & 104 & 362 & 44.7 \\
Wheel 1R & $\mathrm{SC}$ & -330 & 25,780 & 26,380 & 0 & 299 & 0.57 \\
(low rail) & $\mathrm{SF}$ & 1730 & 18,510 & 18,930 & 2 & 209 & 0.56 \\
Wheel 2L & $\mathrm{SC}$ & 14,920 & 600 & 260 & 221 & 0 & 0.55 \\
(high rail) & $\mathrm{SF}$ & 18,480 & 1890 & 1350 & 55 & 0 & 0.58 \\
Wheel 2R & $\mathrm{SC}$ & $-24,890$ & $-19,990$ & 22,430 & 102 & 14 & 26.7 \\
(low rail) & $\mathrm{SF}$ & $-28,600$ & -1720 & 10,200 & 257 & 0 & 9.3 \\
\hline
\end{tabular}

Table 3 presents wear numbers in the rail contact patch reference system, lateral forces in the global reference system, longitudinal and lateral wear numbers and wheel flange-railhead contact angle for the front bogie of vehicle $C O N V$. A graphical representation of the wear numbers is shown in Fig. 11.

Table 4 summarizes angle of attack, total wear numbers and derailment ratios in both simulated cases.

During coasting in horizontal curves of different radii, the advantages of the TFM vehicle were expected to decrease while the curves were less sharp. A large number of simulations were conducted with or without traction, slope and cant deficiency. Comparison results are shown for two typical coasting conditions with high cant deficiency $\left(a_{n c}=1 \mathrm{~m} / \mathrm{s}^{2}, h_{d}=153 \mathrm{~mm}\right)$, for five different curvatures $\left(\rho=1 / R=1, \sqrt{ } 2,2,3\right.$ and $\left.5 \mathrm{~km}^{-1}\right)$ corresponding to $R=1000,707,500,333$ and $200 \mathrm{~m}$, respectively. The same analyses were performed in balance conditions.

Damage index is evaluated for the whole trainsets of $C O N V$ vehicle (6 cars) and TFM vehicle (19 cars), and the results are shown in Fig. 12 for the high rail and low rail. As expected, the TFM vehicle introduces no damage at all in the rail at balance speed, while CONV vehicle is responsible for high rail wear for curves with $R<300 \mathrm{~m}$, and for RCF damages over $R=500 \mathrm{~m}$. When cant deficiency increases, bogie rotation due to centrifugal effects improves vehicle $C O N V$ behaviour, but always showing high rail wear for sharp curves and increasing high rail RCF damages with the increase of the curve radius, while for TFM vehicle, high rail tends to show RCF damages comparable only to curves with $\mathrm{R}>700 \mathrm{~m}$, while low rail again shows no damage (Fig. 13).

\subsection{Effects on Traction and Performances}

As already said, major improvements are expected in those sections where traction/braking is critical. To validate the TFM concept, some specific simulations were conducted in different scenarios.

The first case was a run through a mild curve $(R=1000 \mathrm{~m})$, with moderate cant $(h=80 \mathrm{~mm})$ at balancing speed $(v=22.9 \mathrm{~m} / \mathrm{s})$. This case is particularly interesting as rolling contact fatigue problems happen mostly on mild radius curves, where the use of premium rails showed the well-known problems (see e.g. the Hatfield accident, UK, 17 October 2000).

Both coasting and traction with the maximum torque of $4500 \mathrm{Nm}$ per axle used above were simulated. Wear numbers were obviously taken in transient conditions when traction is applied. The wear number for the front outer wheel of CONV vehicle increased from $71 \mathrm{~J} / \mathrm{m}$ (coasting) to $103 \mathrm{~J} / \mathrm{m}$ (full traction), while $T F M$ wear numbers remained very low, changing from $1-2 \mathrm{~J} / \mathrm{m}$ (coasting) to $3 \mathrm{~J} / \mathrm{m}$ (full traction) per wheel. Therefore, no damage at all is introduced in the rail by the TFM train.

Another simulation was performed with a starting torque of $4500 \mathrm{Nm}$ per wheel, i.e. $9000 \mathrm{Nm}$ per rodal, which, as said above, is compatible with the available space in the rodal and with the current PMSM technology. Conditions chosen for this analysis were the most critical ones already observed (start from standing, $i=50 \%, R=200 \mathrm{~m}, h=160 \mathrm{~mm}$ ). It is worth reminding that vehicle $C O N V$ started slipping at $4500 \mathrm{Nm}$ per axle, with the full trainset introducing damage indexes of -260 for the high rail and -70 for the low rail. Simulations on vehicle TFM led to an astonishing acceleration of $1.16 \mathrm{~m} / \mathrm{s}^{2}$ with damage indexes of 87 for the high rail and 129 for the low rail. These figures show that the performances of a TFM vehicle can be massively superior compared with a conventional vehicle. Moreover, to obtain the usual performances that are requested in purchasing tenders, the TFM vehicle could be equipped with less than $100 \%$ of driven wheels with consistent savings.

\section{Discussion}

The superiority of TFM vehicle over CONV vehicle in terms of rail damage is overwhelming, with a reduction of wear numbers in the order of $1 / 4$ in the worst case to $1 / 400$ in the best case.

Results confirm that expectations on damage introduced by vehicle TFM running in balance conditions were 


\begin{tabular}{|c|c|c|c|c|c|}
\hline Case & Traction & Line type & $\mathrm{v}[\mathrm{m} / \mathrm{s}]$ & $\mathrm{i}[\%]$ & $\mathrm{h}_{\mathrm{d}}[\mathrm{mm}]$ \\
\hline SC & On & & 0 & 50 & 160 \\
\hline SF & On & $\ldots \ldots \ldots \ldots+\ldots$ & 0 & 50 & 0 \\
\hline
\end{tabular}

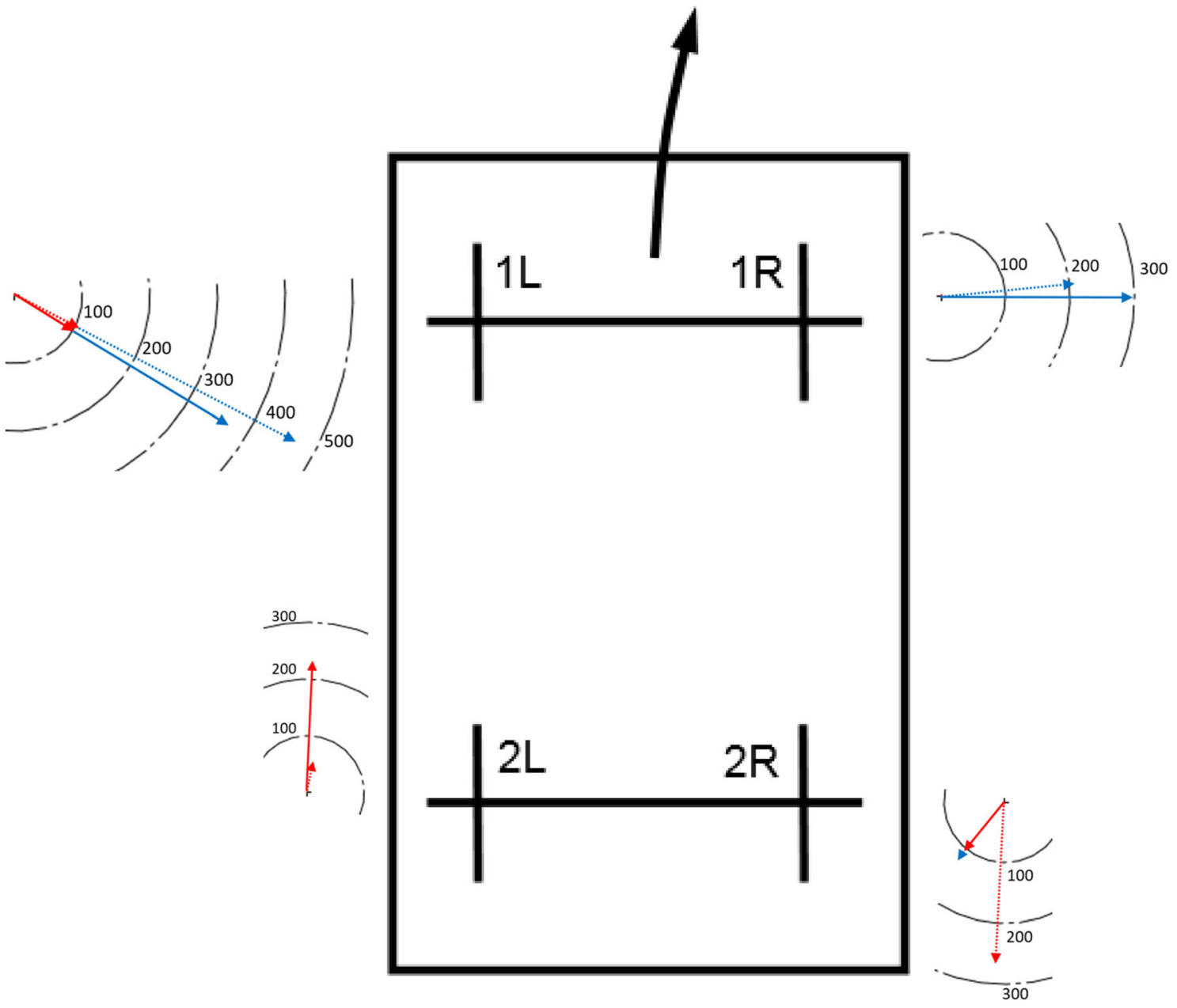

Fig. 11 Plot of wear numbers in the rail contact patch reference

stacked, starting with $T_{x} \gamma_{x}$ (red) and ending with $T_{y} \gamma_{y}$ (blue). It can be system for the front bogie of vehicle $C O N V$ in the five simulated observed that in most of the cases wear numbers are larger on the first scenarios. Vectors lie on the contact patch surface and point in the wheelset, whose lateral forces are dominant on longitudinal forces.

Table 4 Summary of angles of attack, total wear numbers and derailment ratios for sharp curve simulated cases.

\begin{tabular}{|c|c|c|c|c|c|c|c|c|}
\hline \multirow[t]{2}{*}{ Case } & \multirow[t]{2}{*}{ Type } & \multirow{2}{*}{$\begin{array}{l}v \\
{[\mathrm{~m} / \mathrm{s}]}\end{array}$} & \multirow{2}{*}{$\begin{array}{l}i \\
{[\% 0]}\end{array}$} & \multirow{2}{*}{$\begin{array}{l}h_{d} \\
{[\mathrm{~mm}]}\end{array}$} & \multicolumn{2}{|c|}{ Angle of attack [mrad] } & \multicolumn{2}{|l|}{$Y / Q$} \\
\hline & & & & & $\begin{array}{l}\text { CONV } \\
\text { first/second } \\
\text { axle }\end{array}$ & $\begin{array}{l}\text { TFM } \\
\text { first rodal }\end{array}$ & $\begin{array}{l}C O N V \\
\text { high/low rail } \\
\text { front / rear wheelset }\end{array}$ & $\begin{array}{l}\text { TFM } \\
\text { high/low rail } \\
\text { first rodal }\end{array}$ \\
\hline $\mathrm{SC}$ & Traction & 0 & 50 & -160 & $11.7 / 0.8$ & 4.48 & $\begin{array}{l}0.53 /-0.41 \\
-0.01 /-0.25\end{array}$ & $0.44 /-0.35$ \\
\hline SF & Traction & 0 & 50 & 0 & $11.4 / 0.4$ & 0.21 & $0.49 /-0.40$ & $0.02 / 0.00$ \\
\hline
\end{tabular}

fulfilled. Negligible wear numbers are obtained, showing that there is possibly neither wear on the high rail nor corrugation on the low rail. In the same cases, vehicle
CONV exhibits high wear numbers that explain the extensive damages observed even if the vehicle runs in apparently favourable kinematic conditions. 

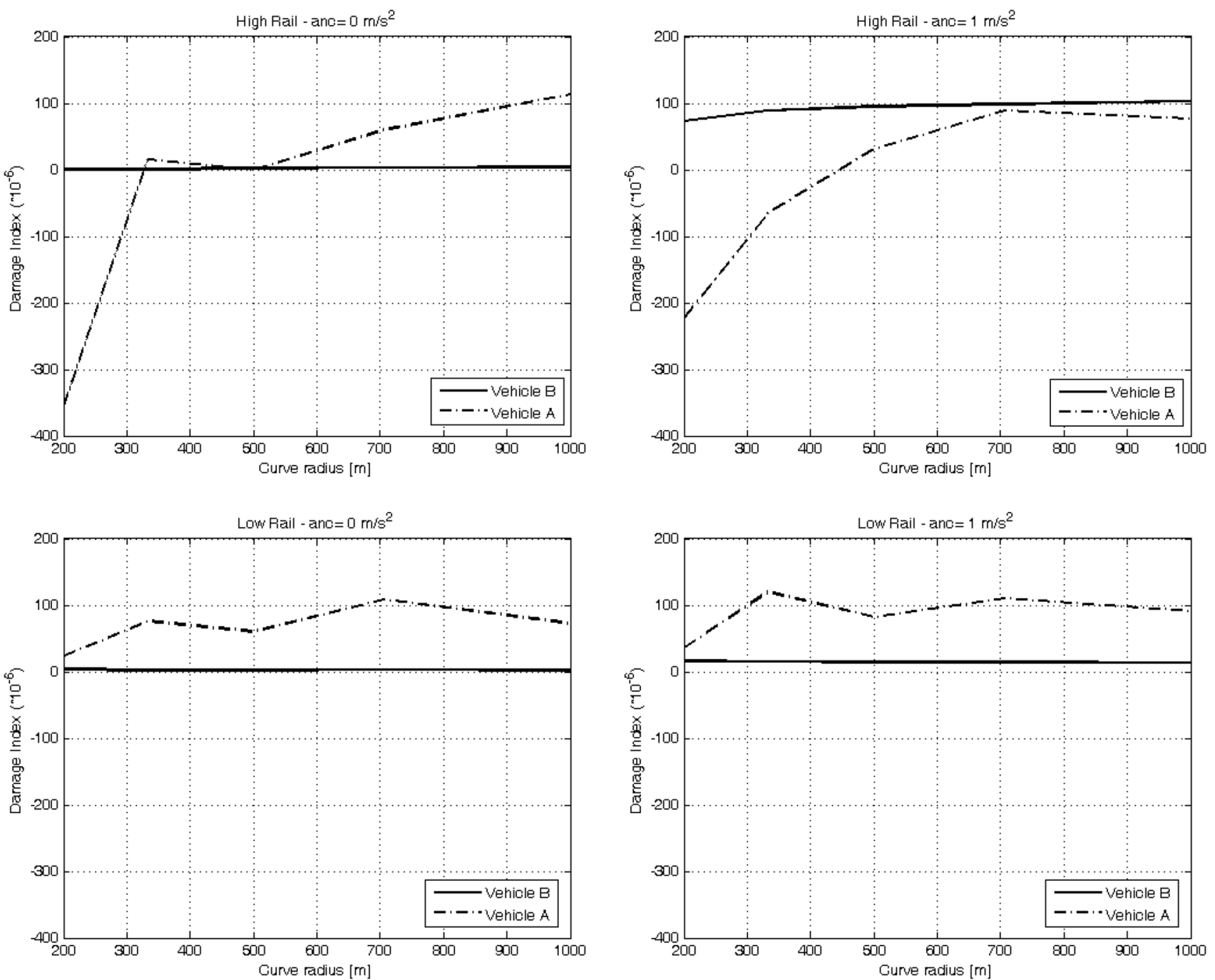

Fig. 12 Wear numbers for high and low rails for complete trainsets CONV (6 cars) and TFM (19 cars) running in curves of different radius at balance speed (top) and at high cant deficiency $\left(a_{n c}=1 \mathrm{~m} / \mathrm{s}^{2}, h_{d}=153 \mathrm{~mm}\right)$ (bottom).
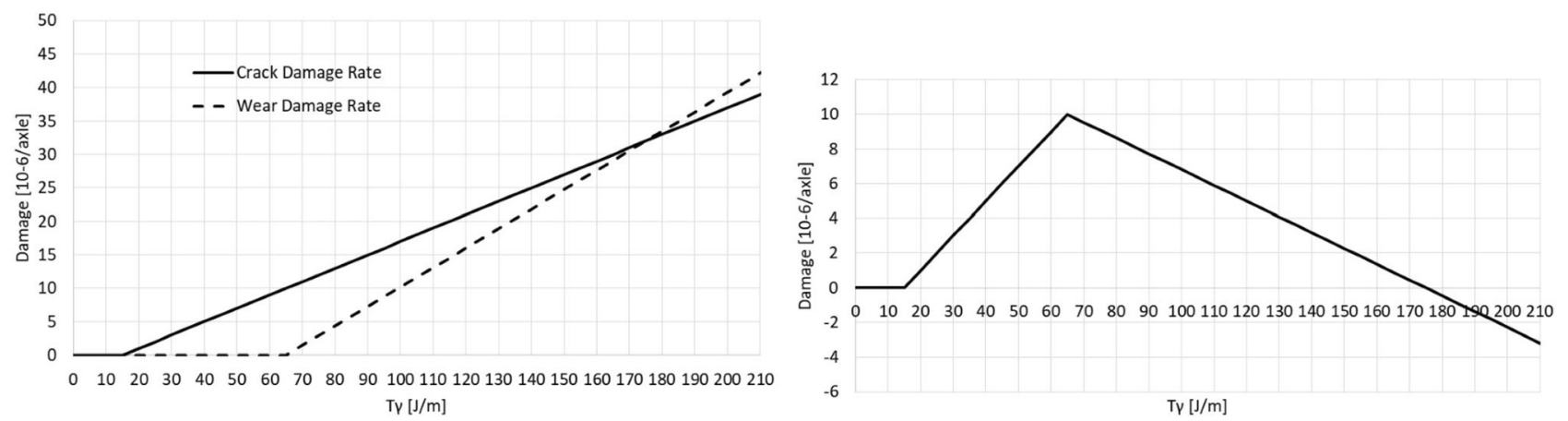

Fig. 13 Assumed damage rate for wear and crack growth as function of Tgamma in the Rail Surface Damage (RSD) model. After the break-even point at $175 \mathrm{~J} / \mathrm{m}$, wear is dominant on RCF and cracks are removed before they grow

Vehicle $T F M$ is superior also in the cases of high cant excess. It can be concluded that the damage introduced in the rail by vehicle $T F M$ is due only to traction forces at balance speed and that also in high-canted track wear numbers are relatively limited despite high gravitational forces. 
Vehicle $C O N V$ exhibits severe wear $(W>175 \mathrm{~J} / \mathrm{m})$ for high rails in curves below $400 \mathrm{~m}$ and $\mathrm{RCF}$ damages ( $W=15-175 \mathrm{~J} / \mathrm{m}$ ) for high rails in curves over $400 \mathrm{~m}$ and for low rail in all curves. This is independent from the operating conditions, i.e. cant deficiency, while TFM vehicle is constantly below the threshold of $15 \mathrm{~J} / \mathrm{m}$ for which no damage is introduced in the rail if running at balanced speed. Only RCF damages can occur on high rail at high cant deficiency. Therefore, a conventional vehicle is able to damage the high rail regardless of whether it is coasting or in traction; on the contrary, vehicle TFM never damages the rail if proper operating condition are chosen.

Although rail damage is central in this paper, safety against derailment must be checked in all situations. Table 4 shows that TFM has derailment coefficients $Y$ I $Q$ lower than $C O N V$. This is not surprising as AOA is very low in any case. Both vehicles, nevertheless, show values much lower than those allowed by running dynamics standard [19].

\section{Conclusions and Further Developments}

The paper has discussed the validation of a concept for a metro vehicle with an uncommon architecture, aimed at a dramatic improvement in track friendliness, i.e. to reduce as much as possible damage to rails that drains considerable resources in every metro lines.

The proposed vehicle, called Track Friendly Metro (TFM), uses a number of concepts (Talgo rodal, independently rotating wheels, gearless drive) that have never been implemented in such class of vehicles. More specifically, the Talgo concept was used only on some trams to obtain the low-floor architecture, beyond mainline vehicles produced by the Spanish company. As a metro is not clearly interested in low-floor concepts, plenty of space (compared with a tram) in the bogie area allowed accommodation of two synchronous permanent magnets motors (PMSM) with a total torque estimated to be $9000 \mathrm{~N} / \mathrm{m}$.

The distinct advantage of the TFM architecture is the ability to align the "single axis of wheelset" always radially, virtually eliminating all creepage in a trailed rodal. Longitudinal creepage is in fact theoretically zero as wheels are freely rotating, while lateral creepage is zero as the rodal is guided by the carbodies and the angle of attack vanishes. The same applies to harsh traction situations, where the superiority of $T F M$ versus $C O N V$ is still very appealing.

While adhesion is partly "wasted" during negotiation of a conventional bogie due to longitudinal and lateral creepage, bigger traction/braking efforts can be obtained with the TFM layout. As wear numbers are much lower, no damage is introduced in the rails and smaller motors can be used. To keep things as simple as possible, a speed control in straight track and a torque control in curves (managed by ATO systems) were used, with very promising results.

According to the current knowledge of full vehicle simulation, wheel-rail contact analysis and material behaviour, the damage introduced by the proposed architecture in the wheel-rail contact is negligible in all conditions. The TFM architecture achieves the highest possible track friendliness. As it is virtually capable of avoiding both wear and RCF damages, it is the best candidate to reach rail maintenance free operations.

Funding Not applicable.

\section{Declarations}

Conflict of interest Not applicable.

Open Access This article is licensed under a Creative Commons Attribution 4.0 International License, which permits use, sharing, adaptation, distribution and reproduction in any medium or format, as long as you give appropriate credit to the original author(s) and the source, provide a link to the Creative Commons licence, and indicate if changes were made. The images or other third party material in this article are included in the article's Creative Commons licence, unless indicated otherwise in a credit line to the material. If material is not included in the article's Creative Commons licence and your intended use is not permitted by statutory regulation or exceeds the permitted use, you will need to obtain permission directly from the copyright holder. To view a copy of this licence, visit http://creativecommons. org/licenses/by/4.0/.

\section{References}

1. Bracciali A (2006) Rail corrugation growth in a metro curve, In: Proc 7th international conference on contact mechanics and wear of rail/wheel systems, Brisbane, Australia, September 24-27

2. Stock R, Stanlake L, Hardwick C, Yu M, Eadie D, Lewis R (2016) Material concepts for top of rail friction management classification characterisation and application. Wear 366:7225-7232. https://doi.org/10.1016/j.wear.2016.05.028

3. Wickens A (2003) Fundamentals of rail vehicle dynamics: guidance and stability, Swets \& Zeitlinger B.V., Lisse, The Netherlands, ISBN 90-265-1946-X

4. Eickhoff B (2010) Wheel-rail interface interactions. In: Schmidt $\mathrm{F}$ et al (eds) Wheel-rail best practice handbook. University of Birmingham Press

5. Bracciali A, Piccioli F (2014) Elimination of failures in railway gearboxes by regenerative coasting, In: J. Pombo (Eds), Proceedings of the second international conference on railway technology: research, development and maintenance“, Ajaccio, Corsica, 8-11.4.2014, Civil-Comp Press, Stirlingshire, UK, Paper 312, 2014. https://doi.org/10.4203/ccp.104.312

6. Bracciali A, Piccioli F (2014) Effect of load on vibrations of a railway gearbox, In: Pombo J (Eds.) Proceedings of the second international conference on railway technology: research, development and maintenance, Ajaccio, Corsica, 8-11.4.2014, CivilComp Press, Stirlingshire, UK, Paper 306, 2014. https://doi.org/ 10.4203/ccp.104.306. 
7. Grassie SL, Elkins JA (2005) Tractive effort, curving and surface damage of rails - Part 1. Forces exerted on the rails. Wear 258:1235-1244. https://doi.org/10.1016/j.wear.2004.03.064

8. Grassie SL, Elkins JA (2006) Traction and curving behaviour of a railway bogie. Veh Syst Dyn 44:883-891. https://doi.org/10. 1080/00423110600907451

9. Elia A (1998) Fiat Pendolino: developments, experiences and perspectives. Proc Instn Mech Engrs Part F 212(1):7-17. https:// doi.org/10.1243/0954409981530643

10. José Luis López Gómez, Trenes Talgo pendulares y de alta o muy alta velocidad, https://www.aecientificos.es/trenes-talgo-pendu lares-y-de-alta-o-muy-alta-velocidad/, Accessed on 25.03.2021.

11. Bracciali A (2016) Railway wheelsets: history, research and developments. Int J Railw Technol 5(1):23-52. https://doi.org/10. 4203/ijrt.5.1.2

12. Hondius H (1992) The development of low-floor trams. J Adv Transp 27:79-102

13. Ultra Low Floor, https://de.wikipedia.org/wiki/Ultra_Low_Floor, Accessed on 25.03.2021

14. Krettek O (1998) Running behaviour of the single wheel and its influence illustrated by example of the ULF Ultra Low Floor tramcar of the Vienna transport authorities, In: 5th mini conference on the vehicle system dynamics, identification and anomalies, Budapest, pp 183-201

15. Stadler Variobahn, https://en.wikipedia.org/wiki/Stadler_Var iobahn, Accessed on 25.03.2021

16. Škoda $15 \mathrm{~T}$, https://en.wikipedia.org/wiki/\%C5\%A0koda_15_T, Accessed on 25.03.2021

17. Kolar J (2015) Design of a wheelset drive. Trans Electr Eng 4:11-19
18. Peroutka Z, Zeman K, Krus F, Kosta F (2009) New generation of full low-floor trams: control of wheel drives with permanent magnet synchronous motors, In: 2009 IEEE energy conversion congress and exposition, San Jose, CA, USA, 2009, pp 18331840, https://doi.org/10.1109/ECCE.2009.5316438

19. EN 14363:2016+A1 (2016) Railway applications - testing and simulation for the acceptance of running characteristics of railway vehicles - running behaviour and stationary tests, CEN, Brussels

20. Elkins JA, Eickhoff BM (1982) Advances in nonlinear wheel/rail force prediction methods and their validation. J Dyn Sys Meas Control 104(2):133-142. https://doi.org/10.1115/1.3139688

21. Burstow MC (2003) A model to predict and understand rolling contact fatigue in wheels and rails, AEA Technology Rail, Derby

22. Öberg J, Andersson E (2009) Determining deterioration cost for railway tracks, Proc I Mech E F J Rail Rapid Transit, 223: 121-129 https://doi.org/10.1243/09544097JRRT222

23. Commission Regulation (EU) No 1299/2014 of 18 November 2014 on the technical specifications for interoperability relating to the 'infrastructure' subsystem of the rail system in the European Union. https://eur-lex.europa.eu/legal-content/EN/TXT/ ?uri=CELEX:02014R1299-20190616 Accessed on 28.03.2021

24. Vi-Grade Engineering Software \& Service (2017) Vi-Rail 18.0 Documentation, Vi-Grade GmbH, Marburg, Germany

25. Kalker JJ (1982) A fast algorithm for the simplified theory of rolling-contact. Veh Syst Dyn 11(1):1-13 